\title{
Assessment of Groundwater Potential in Ozoro, Delta State, Nigeria Using the Electrical Resistivity Method
}

\author{
Ochuko Anomohanran ${ }^{1}$ \\ ${ }^{1}$ Physics Department, Faculty of Science, Delta State University, Abraka, Nigeria \\ Correspondence: Ochuko Anomohanran, Physics Department, Delta State University, Abraka Via Warri, Delta \\ State, Nigeria. Tel: 234-803-948-8655. E-mail: mrochuko@yahoo.com
}

Received: September 6, 2014 Accepted: September 18, 2014 Online Published: September 21, 2014

doi:10.5539/apr.v6n5p116

URL: http://dx.doi.org/10.5539/apr.v6n5p116

\begin{abstract}
Electrical resistivity survey involving six vertical electrical soundings was conducted in Ozoro to assess the groundwater potential of the area. Record of apparent resistivity and electrode spread were analysed using curve matching and computer iteration technique and the outcome compared with record of existing borehole. Result revealed the presence of four geoelectric strata which are topsoil, fine-medium grain sand, clay-clayey sand and coarse-medium coarse sand. The fourth layer with a resistivity range of 648-917 $\Omega \mathrm{m}$ and depth range of 10.7-18.0 $\mathrm{m}$ is identified as the aquifer layer. Result also revealed that the aquifer layer is overlaid by a clayey aquitard of 4.2 $\mathrm{m}$ thick. It is recommended that the sourcing of water for domestic purpose by the people should be done in excess of $18.0 \mathrm{~m}$.
\end{abstract}

Keywords: groundwater, electrical resistivity method, aquifer, vertical electrical sounding, schlumberger array

\section{Introduction}

Exploration of groundwater has been the surest way to handle the ever increasing need for fresh and quality water used either for domestic, agricultural or industrial purpose. This is because of its relative abundance and quality with respect to many other sources. The development of this very important resource in Nigeria has not yielded a very impressive result that is commensurate with the financial resources expended on it (Edet \& Okereke, 2014). This has therefore impeded the supply of quality water to a good percentage of the people of this country. Perdomo et al. (2014), emphasize the fact that limited fund has also hampered the provision of water and the availability of necessary information to help assess this resource in developing countries.

Assessing groundwater requires detailed geophysical exercise which includes geophysical well logging, seismic, magnetic, electrical method, inseam drilling and geographic information system. In a bid to effectively tap the groundwater resource, a method which is able to evaluate the aquifer layer, groundwater vulnerability, and quality is necessary. The electrical resistivity method is readily available to achieve all of these. This is because it can determine the resistivity variation of the various earth strata (Ibrahim, 2013).

The electrical resistivity method has been a very significant instrument employed in exploring the earth for groundwater (Lowrie, 2004). Electrical resistivity has been employed greatly to investigate or probe the subsurface layers of the earth. This is because it is able to distinguish between sandy and clayey formation, porous and impermeable rock, and fresh and saline water aquifers. It is used to obtain information concerning the subsurface layers and the location of groundwater (Ibrahim, 2013). The contrasts in the electrical resistivity of various lithological sequences in the subsurface are used to delineate the subsurface layers and assess the groundwater prospect of the area (Aanuoluwa \& Ayobami, 2012).

Electrical resistivity surveys are carried out through an electrical resistivity sounding or horizontal profiling. The electrical resistivity sounding indicate the differences in apparent resistivity of the subsurface formation with respect to the depth while the horizontal profiling is employed to determine lateral variations in impedance (Anomohanran, 2014). In a situation where the space between the current electrodes and the potential electrodes are increased, it is observed that the current will move deeper through the ground and influence the apparent resistivity to greater depths (Todd, 2004). 


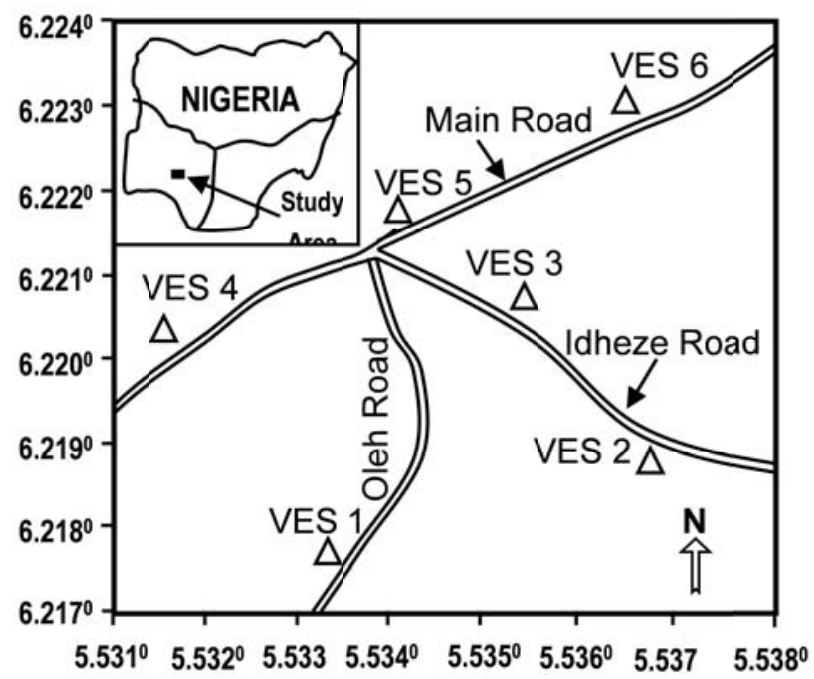

Figure 1. Site Map Showing the Sounding positions

Two electrode arrays are basically used in the resistivity sounding technique. They are the Wenner and the Schlumberger arrays. However, the Schlumberger array is most conveniently used for electrical sounding (Fetter, 2007). In the Schlumberger array, only the inner potential electrodes are kept constant, but are moved occasionally only when the incoming signal becomes too weak (Anomohanran, 2014). But the current or outer electrodes are moved each time a new set of reading is required. Nevertheless, in the Wenner array, the four electrodes are moved each time a reading is to be taken. The exercise involves the four electrodes being moved to a new position by increasing $\mathrm{AB} / 2$ each time a measurement is made. The apparent resistivity obtained in the sounding process is plotted on a logarithmic paper as a function of electrode spacing and interpreted (Fetter, 2007).

The provision of quality water to rural and semi-rural communities have been identified as being essential in handling quite a number of common diseases. This notwithstanding, the inadequate supply of potable water in Ozoro can be classified as going bad by the day. This is as a result of the absence of public water supply in addition to the worsening case of people note sourcing water from hygienically healthy sources. The major source of water for the people has been shallow wells and surface water which are prone to pollution.

As a result of the prevailing problems associated with these sources of water to meet domestic needs, it has become imperative to carry out a geophysical survey to enable the residents of the area source quality water to satisfy their domestic requirements. This survey is carried out to determine the geoelectric formations in the area, identify the aquifer stratum and the depth of the aquifer in the area. This work will provide the necessary information that will assist the people in solving their acute water shortage.

\section{Materials and Methods}

\subsection{Location and Geology of the Study Area.}

Ozoro is the administrative headquarters of the Isoko North Local Government Area of Delta State. The study area lies from longitude $5.531^{0} \mathrm{E}$ to $5.537^{\circ} \mathrm{E}$ and latitude of $6.217^{\circ} \mathrm{N}$ to $6.224^{0} \mathrm{~N}$ (Figure 1). The area is in the tropical rainforest area of the Niger-Delta. The climate is marked by two distinct seasons, namely the dry and the rainy seasons. The dry season lasts from November to April while the rainy season spans from May to October. The Niger Delta area is characterized by three distinct formations. The first, which is also the water bearing formation across the area is the Benin formation which is about $1800 \mathrm{~m}$ deep. It is made largely of sand with a minor component of shale. The second formation is the Agbada formation which is an equal collection of sand and shale. The third strategraphic formation is the Akata formation which is mainly shale in composition (Anomohanran, 2014).

\subsection{Field Procedure}

This study was carried out to investigate the electrical conductivity variation of the formations. In doing this, six vertical electrical soundings using the Schlumberger electrode array with maximum current electrode spacing of $300 \mathrm{~m}$ was employed. The ABEM SAS 1000 Terrameter which is an averaging equipment was utilized as the field instrument. This instrument is capable of displaying the apparent resistivity of the ground layers. The current 
electrode spacing was increased in steps about a fixed point while maintaining the spacing between the potential electrodes until it became necessary to increase the potential electrode as the ground response becomes weak. The data obtained were interpreted first by partial curve matching using the master curves and the model parameters obtained were then employed as the input parameters in the computer based interpretation using the Resist software.
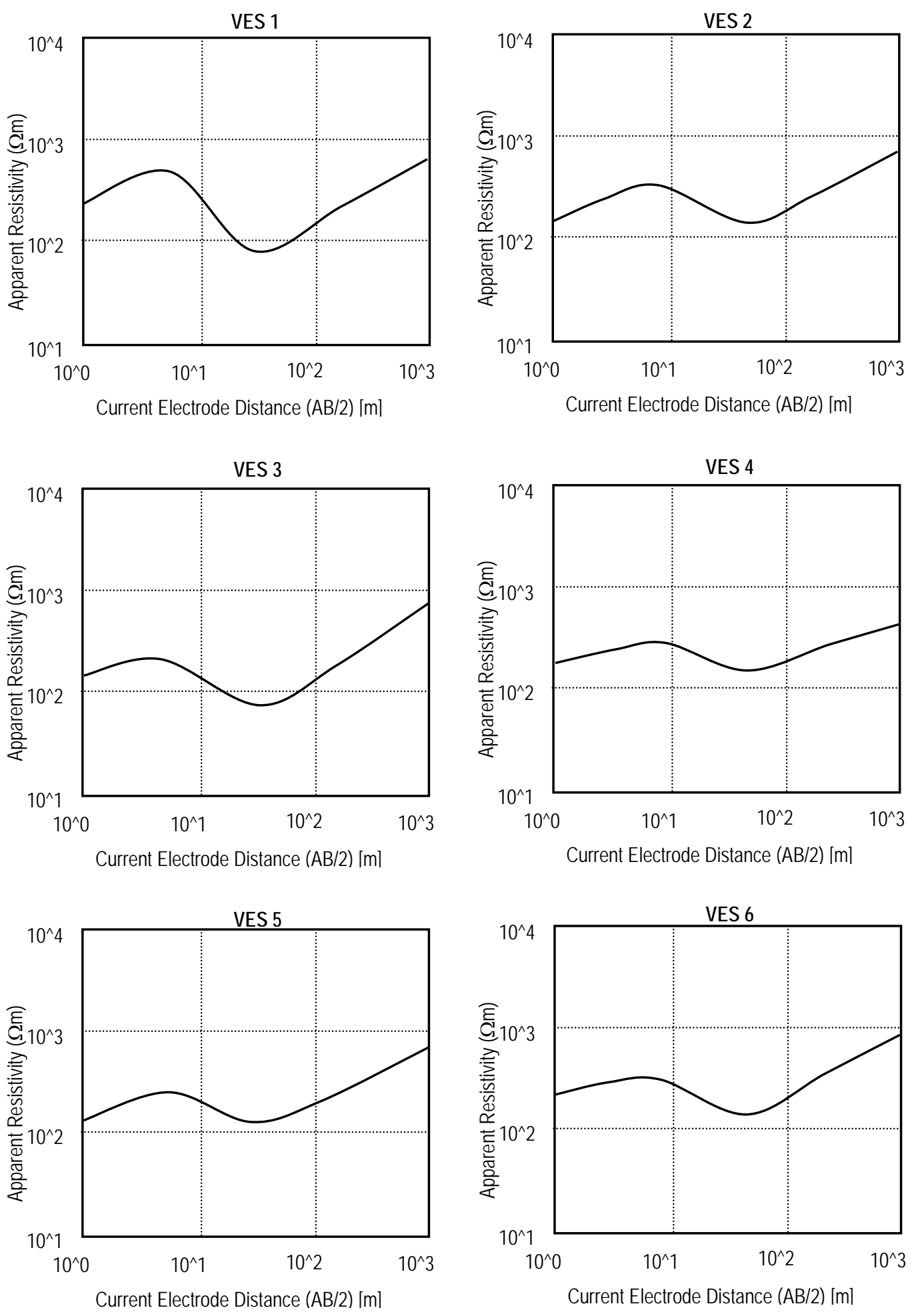

Figure 2. Sounding Curves Obtained from Study Area 

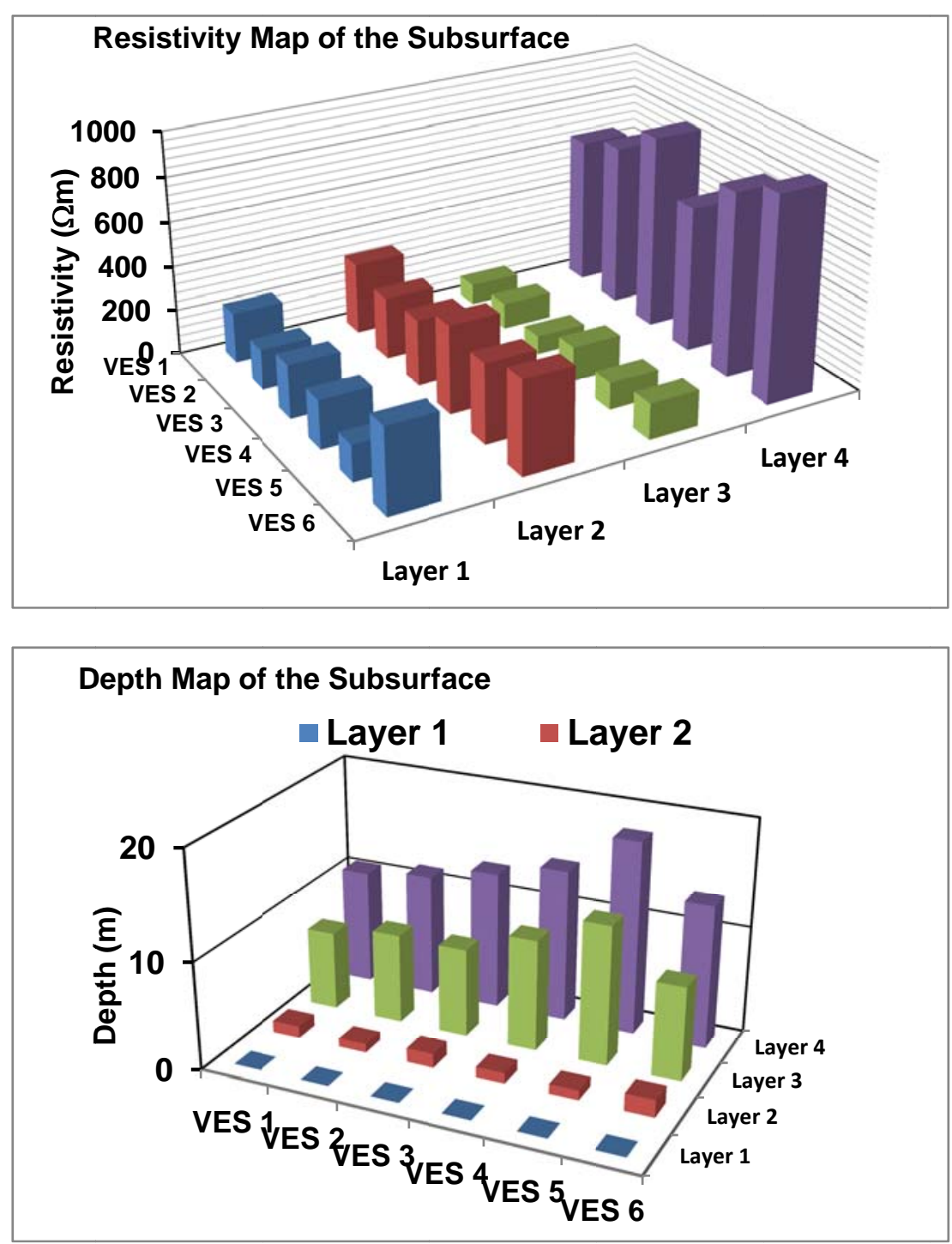

Figure 3. Result of Geophysical Interpretation

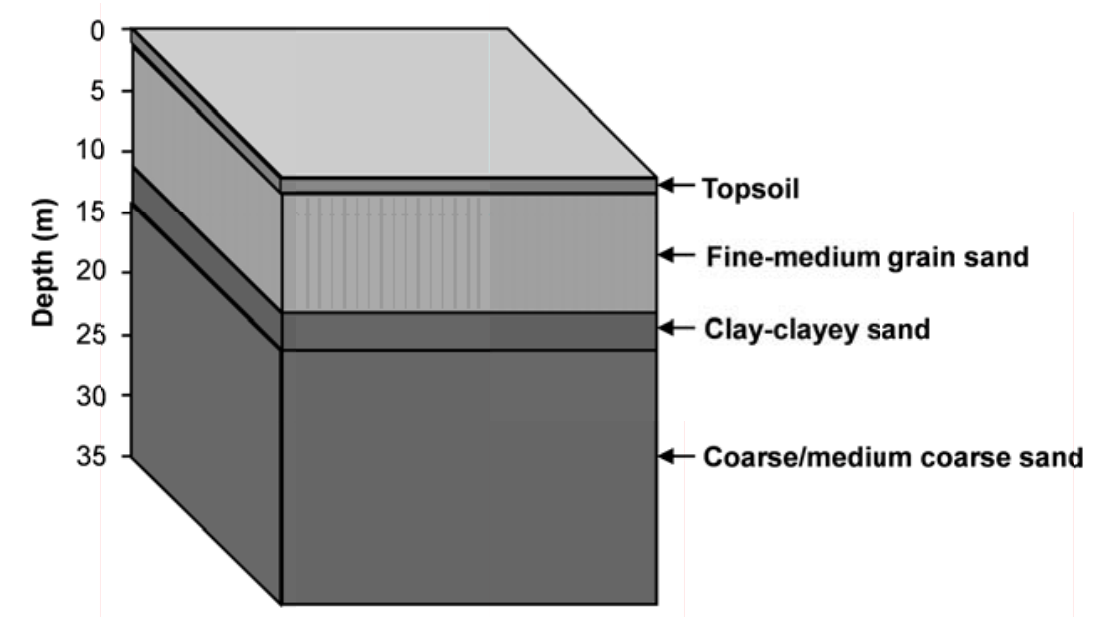

Figure 4. Plot showing the Subsurface Formations in the Study Area 


\section{Results and Discussion}

The data obtained from the field survey were interpreted both qualitatively and quantitatively. The resulting sounding curve obtained from the interpretation is presented as Figure 2. This figure shows that the resistivity curve types are mainly $\mathrm{KH}$ which are diagnostic of semi-confined or confined aquifers. The result of the quantitative interpretation is as shown in Figure 3. The result presented in Figure 3 was compared with record of existing borehole and the outcome shows close correlation between the field record and the log details. Figure 3 shows the resistivity values of the various formations observed in the area and also their depth from the earth's surface. The outcome of this study has indicated the existence of four formations (Figure 4). These are the topsoil, fine-medium grain sand, clay-clayey sand and coarse-medium coarse sand.

The first layer which is topsoil has a resistivity range of 160 to $376 \Omega \mathrm{m}$ and a thickness range of 0.8 to $1.6 \mathrm{~m}$. Underlying the topsoil is a fine-medium grain sand formation having resistivity range of between 275 and $414 \Omega \mathrm{m}$ and a thickness range of between 6.2 and $12.0 \mathrm{~m}$. This layer is an unconfined aquifer, which cannot be relied upon to provide adequate water for the people at all times. Besides the water content, this stratum will be very vulnerable to pollution from dumpsites and septic tanks.

The third layer is composed of sandy clay in VES 1, 2, 3 and 5 while VES 4 and 6 are clayey sand. The resistivity of this layer range between 83 and $160 \Omega \mathrm{m}$ while the thickness range between 3.1 and $5.1 \mathrm{~m}$. This layer is fairly impermeable and hence could resist the influx of contaminants to the underlying layers. The fourth layer is made up of coarse sand in VES 1, 2 and 4 while it is medium coarse sand in VES 3, 5 and 6. The resistivity range of this layer falls between 648 and $917 \Omega \mathrm{m}$ while the depth range is between 10.7 and $18.0 \mathrm{~m}$. This layer is the water bearing horizon in the area and is protected by the overlying clayey formation. Sourcing of groundwater for domestic and agricultural uses can therefore be made to the fourth layer aquifer.

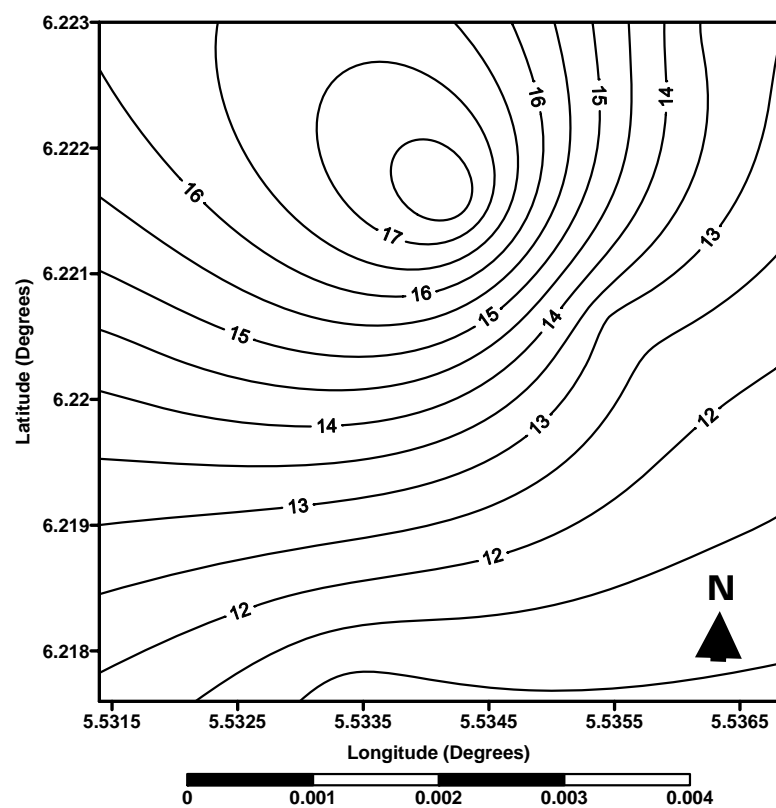

Figure 5. Depth Contour Map of the Aquifer Layer

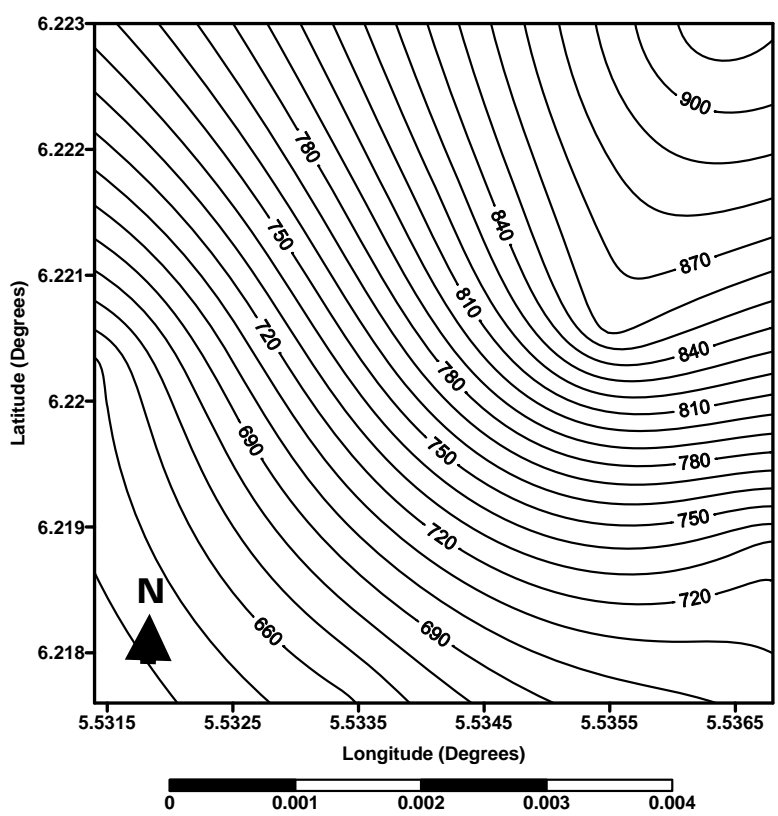

Figure 6. Resistivity Contour Map of the Aquifer Layer

The contour map showing the depth to drill in order to strike the top of the aquifer is presented in Figure 5. This will assist the people of the area to know the depth to drill in order to obtain water from the fourth aquifer. The depth to the aquifer layer increases as you move northward meaning that the depth of boreholes sank in the area will deepen as you travel northward. The resistivity map of the aquifer layer is presented in Figure 6. This figure shows that the resistivity of the aquifer increases in the northeast direction. It therefore implies that the layer toward the northeast will be more prolific and will be of interest in the development of groundwater in the area.

\section{Conclusion}

The vertical electrical sounding has been conducted in this study to assess the groundwater potential of the area. The data from the survey were interpreted qualitatively and quantitatively and the result showed the presence of four geoelectric layers comprising of topsoil, fine-medium grain sand, clay-clayey sand and coarse-medium coarse 
sand. The fourth formation with a depth range of 10.7 to $18.0 \Omega \mathrm{m}$ is identified as the aquifer zone. The survey has also demonstrated that the aquifer is covered by a fairly impermeable layer that is $4.2 \mathrm{~m}$ thick. Groundwater for domestic, industrial and agricultural use is suggested to be tapped from the fourth layer aquifer.

\section{References}

Aanuoluwa, A. T., \& Ayobami, S. L. (2012). Geoelectric assessment of groundwater prospect and vulnerability of overburden aquifers at Adumasun area, Oniye, Southwestern Nigeria. Archives of Applied Science Research, 4(5), 2077-2093.

Anomohanran, O. (2014). Hydrogeophysical and Hydrogeological Investigations of Groundwater Resources in Delta Central, Nigeria. Journal of Taibah University for Science. http://dx.doi.org/10.1016/j.jtusci.2014. 06.003

Edet, A., \& Okereke, C. S. (2014). Hydrogeologic Framework of the Shallow Aquifers in the Ikom-Mamfe Embayment, Nigeria using an Integrated Approach. Journal of African Earth Sciences, 92, 25-44. http://dx.doi.org/10.1016/j.jafrearsci.2014.01.004

Fetter, C. W. (2007). Applied Hydrogeology (2nd ed.). New Delhi: CBS Publishers.

Ibrahim, E. (2013). Geoelectric resistivity survey for site investigation in east Matruh area, north western desert, Egypt. World Applied Sciences Journal, 21(7), 1008-1016. http://dx.doi.org/10.5829/idosi.wasj.2013. 21.7.2871

Lowrie, W. (2004). Fundamentals of Geophysics (1st 2ed.). United Kingdom: Cambridge University Press.

Perdomo, S., Ainchil, J. E., \& Kruse, E. (2014). Hydraulic parameters estimation from well logging resistivity and geoelectrical measurements. Journal of Applied Geophysics, 105, 50-58. http://dx.doi.org/10.1016/j. jappgeo.2014.02.020

Todd, D. K. (2004). Groundwater Hydrology (2nd ed.). New York: John Wiley.

\section{Copyrights}

Copyright for this article is retained by the author(s), with first publication rights granted to the journal.

This is an open-access article distributed under the terms and conditions of the Creative Commons Attribution license (http://creativecommons.org/licenses/by/3.0/). 